Çukurova Üniversitesi Mühendislik Fakültesi Dergisi, 36(2), ss. 305-315, Haziran 2021

Cukurova University Journal of the Faculty of Engineering, 36(2), pp. 305-315, June 2021

\title{
Yüksek Gerilim Kabloları için Güvenilir Mekanik Konektör Tasarımı ve Direnç Kontrol Analizi
}

\author{
Ahmet FEYZİŎLU' \\ ${ }^{1}$ Marmara Üniversitesi, Teknoloji Fakültesi, Makine Mühendisliği Bölümü, İstanbul
}

$\ddot{\mathbf{O z}}$

Geliş tarihi: 19.03 .2021

Kabul tarihi: 30.06 .2021

Yüksek gerilim kabloları, elektrik iletim şebekelerinin ve özellikle de elektrik dağıtım şebekelerinin değişmez ve en önemli parçalarıdır. Bu kabloların uzunluğu sınırlı olduğundan enerji hatlarının devamlılı̆ıını sağlayacak kablo bağlantı mekanizmaları kullanılması gerekmektedir. Bu çalışmada, elektrik iletiminde yüksek gerilim kablo sistemleri için bağlantı elemanı olarak kullanılan mekanik konektörlerin optimum özelliklere sahip tasarımının geliştirilmesi ve prototip üretimi amaçlanmıştır. Bu amaç doğrultusunda konektörün bozunma mekanizmaları ve konektör tasarım gereksinimleri araştırılarak 4 farklı tasarım geliştirilmiştir. Bu mekanik konektörler, 154 kV'lık taşıma kapasitesi ve $700 \pm 100 \mathrm{~mm}^{2}$ kesit alanı özelliklere sahip bakır kablolar için geliştirilmiş olup tel kesitine göre yapılandırılabilir niteliktedir. Geliştirilen tasarımlar matematiksel modelleme ortamına aktarılarak mukavemet analizleri yapılmış yer değiştirme $(\mathrm{m})$ ve güvenlik katsayıları incelenmiştir. Mukavemet sonuçlarının uygunluğunun incelenmesi takiben tasarımların kanıtlaması için üretimi yapılmıştır. Güç sistemi ve konektörlerin bulunduğu yüksek gerilim hattından oluşan test düzeneği üzerinde 70'şer dakikalık 50'şer yük çevrim testi yapılarak direnç, akım ve gerilim değerleri gözlemlenmiştir ve uygunluğu (VDE 0220 ve CENELEC standartlarına uygun) incelenmiştir.

Anahtar Kelimeler: Yüksek gerilim, Konektör, Mekanik tasarım, Kablo bağlantı mekanizmaları

\section{Reliable Mechanical Connector Design and Resistance Control Analysis for High Voltage Cables}

\begin{abstract}
High voltage cables are the most important and unchangeable parts of electricity transmission networks and especially electricity distribution networks. Since the length of these cables is limited, it is necessary to use cable connection mechanisms to ensure the continuity of power lines. In this study, it is aimed to develop the optimum design and prototype production of mechanical connectors used as connecting elements for high voltage cable systems in electrical transmission. For this purpose, 4 different designs have been developed by investigating the degradation mechanisms of the connector and the connector design requirements. These mechanical connectors have been developed for copper cables with a carrying capacity of $154 \mathrm{kV}$ and a cross section of $700+-100 \mathrm{~mm}^{2}$ and are configurable according to the wire cross section. The developed designs were transferred to the mathematical modelling platform and their strength analysis was made and the displacement $(\mathrm{m})$ and safety coefficients were examined. After examining the suitability
\end{abstract}

*Sorumlu yazar (Corresponding author): Ahmet FEYZİĞLU, ahmet.feyzioglu@marmara.edu.tr 
of strength results, prototypes of designs were produced. Resistance, current and voltage values were observed by performing 50 load cycle tests for 70 minutes and their suitability (in accordance with VDE 0220 and CENELEC standards) was examined.

Keywords: High voltage, Connector, Mechanical design, Cable connectors

\section{GÍRIŞ}

Son yıllarda şehirlerde artan nüfus yoğunluğu ve elektrikli eşyaların çeşitlenip ucuzlaması neticesinde daha çok insanın kullanımına girmesi elektrik aktarım ve dağıtım sistemlerinin eskisinden çok daha fazla yük taşımasına ve dolayısıyla daha yüksek operasyon sıcaklıklarında çalışmak zorunda kalmasına neden olmuştur. Deneysel sonuçlar ve servis raporları daha güvenilir güç bağlantılarının şu an kullanımda olan rutin teçhizat ve metotlarla sağlanamayacağını ortaya koymuştur [1,2]. Bunun yanında, servis vermekte olan konektörlerin ne kadar bozunmaya uğradığı düzgün bir biçimde ortaya konulamadığı için bakım aralıkları kestirilememektedir [3-8]. Değişik yükleme koşulları altında bağlantı elemanı materyallerinin bozunma mekanizmaları hala tam olarak bilinmemektedir. Bunun başlıca iki sebebi vardır; ilki konektör bozunumu zamanla oluştuğu için saha tecrübesi ortaya net bir bilgi koymamaktadır, ikinci ve asıl önemlisi ise başarısızlığa uğramış konektörlerin termal kaçaklarla ilintili olması neticesinde, konektörün hangi bozunma mekanizması sonucu başarısızlığa uğramış olduğunun teşhis edilememesidir [9-11]. Bu durum konektörler için uygun materyal ve metotların seçilememesi ve dolayısıyla yeterince güvenilir konektörlerin üretilememesiyle sonuçlanmaktadır. Konektörler genellikle elektrik networklerinin zayıf halkaları olarak bilinmektedirler. Konektörlerin stabilitelerini kaybetmesi çoğu zaman tüm elektrik networkünün bozulmasıly sonuçlanır. $\mathrm{Bu}$ durumun ortaya çıkmasında konektörlerin zamanla kimyasal bozunmaya uğramasının yanında, kusurlu montaj sonucu ortaya çıkan fiziksel bozunmalar da önemli yer tutmaktadır [12].

Yüksek gerilim yeraltı kablolarının üretimi esnasında karşılaşılan mekanik sınırlamalar (üretim tekniği gereği karşılaşılan doğal sınırlamalar) ve sevkiyatı sırasında karşılaşılan engeller nedeniyle kablolar sınırlı uzunluklarda üretilmekten olup; enerji hattının devamlılığını sağlamak adına sınırlı kablo uzunlukları yüksek gerilim kablo ekleri yani konektörler ile birleştirilerek istenilen hat devamlılığı sağlanmaktadır [13]. Literatürde iletkenler arasındaki elektriksel bağlantıların mekanik, kaynaşma-lehim (füzyon) veya basınç (kompresyon) gibi birleştirme yöntemleri ile yapıldığı görülmüştür. $\mathrm{Bu}$ doğrultuda montaj yöntemlerine ve yapılarına göre farklı şekillerde 3 çeşit konektör ortaya çıkmaktadır. Bunlar mekanik, kompresyon ve füzyon konektörlerdir [14].

Füzyon, lehimleme ve sert lehimlemede olduğu gibi iki ana metalin veya üçüncü bir metalin eritilerek birleştirilmesini içerir. $\mathrm{Bu}$ yöntem elektrik bağlantılarını birleştirmenin en eski yöntemlerinden biridir. İyi yapılmış bir lehimli bağlantı iyi bir bağlantıdır, ancak kalite doğrudan beceriye bağlıdır ve inceleme neredeyse imkansızdır. Lehimleme, farklı metaller ve akıların eklenmesiyle korozyon olasılığını artırır. Ayrıca lehimleme sertleştirme yoluyla iletkeni zayıflatabilir ve isı bitişikteki kablo yalıtımına zarar verebilir. Lehimin düşük erime noktası, aşırı yük koşullarında eklemin arızalanmasına neden olabilir [15].

Kompresyon-basınç bağlantıları, ana metallerdeki çakışan uçlar arasındaki fiziksel temasla yapılır. Uygun basınçta bile konektörden itibaren uçlar deforme olabilmekte ve daha büyük bir temas ve iletken alan oluşabilmektedir [16]. Ayrıca farklı iletkenlerin ve/veya konektörlerin eşit olmayan genişlemeleri nedeniyle, iletken ve konektör arasında boşluklar yeniden oluşabilmektedir [17]. Bağlantı hava geçirmez değilse, bu boşluklar oksitlerin oluşması için bir yer sağlamış olur [18].

Yüksek ve orta gerilim hatlarında bahsedilen 3 tip konektörden sadece iki tipinin (mekanik, kompresyon) kullanıldığı görülmektedir [14]. Ayrıca yüksek ve orta gerilim alanlarında yapılan çalışmalar incelendiğinde, çalışmaların genellikle 
kompresyon konektörler üzerinde olduğu görülmektedir [19]. Kompresyon ve mekanik konektör kıyaslandığında mekanik konektör sahip olduğu özelliklerden dolayı daha avantajlıdır ve kullanımı daha yaygındır. Bu özellikler:

1- Kompresyon konektörde her enine kesit için özel bir kıvrım konektörü gereklidir. Mekanik konektör alçak ve orta gerilim uygulamaları için iletken kesiti ile ilgili aralıkları alır. Aksesuarların kesit aralığına uyarlanmıştır.

2- Kompresyon konektörde bakır iletkenin bakır konektöre, alüminyum iletkenin alüminyum konektöre ihtiyacı vardır. Mekanik konektör yuvarlak veya sektörel şekilli olabilen örgülü veya tek damarlı bakır ve alüminyum iletkenler bağlanabilir.

3- Kompresyon konektör kurulumu için ağır aletler ve çok sayıda farklı kalıp gereklidir. Mekanik konektör kurulum için özel bir alet gerektirmez.

Konektörlerde bir diğer sorun ise aşırı 1sınmadır. Kablo bağlantıları bir kablo sistemindeki en zayıf bağlantılardır ve arızası esas olarak dahili aşırı 1sınmadan kaynaklanmaktadir [20-23]. Kablo bağlantısında, en yüksek sıcaklık genellikle kompresyon konektöründe bulunur [24]. Kompresyon konektörü oldukça büyük bir bağlantı direncine sahipse, kablo bağlantısında yerel aşırı 1sınmaya neden olan büyük miktarda isı üretilebilir.

Bahsedilen araştırmalar değerlendirildiğinde güvenilir konektör tasarımında konektörlerin neden başarısızlığa uğradığının iyi analiz edilmesi gerekliliği ortaya çıkmaktadır. Bozunmalara karşı dayanımı yüksek konektör üretmek, baskın başarısızlık mekanizmalarına karşı materyal dayanımı teorik ve deneysel olarak ispatlanmasıyla, kullanılması gereken ek kimyasallar ve/veya ekipmanlar varsa saptanmasıyla gerçekleştirilebilir. Hatalı montajdan kaynaklanan fiziksel hasarların azaltılması ise montajı kolay ve tecrübeli iş gücü gerektirmeyen konektörlerin tasarımıla sağlanabilir. Bu çalışmada mekanik ve malzeme avantajlarından dolayı yüksek gerilim hatlarında kullanılmak üzere mekanik konektör tasarımının geliştirilmesi amaçlanmıştır. Tasarımı takiben prototip üretimi yapıldıktan sonra gerekli simülasyon ve testlerin uygulanarak optimum özelliklere sahip mekanik konektörün geliștirilmesi hedeflenmiştir.

\section{MATERYAL VE METOT}

\subsection{Konektör Çeşitleri}

Elektrik hatlarını oluşturan çeşitli çaplardaki kabloları bağlamada kullanılan, montaj yöntemlerine ve yapılarına göre farklı şekillerde konektör çeşitleri vardır. $\mathrm{Bu}$ çeşitlerden en önemlileri mekanik, kompresyon ve füzyon tipte olanlardır.

Mekanik Konektör: Donanımın veya benzer mekanik unsurların üzerinde mekanik sistem vasıtasıyla temas noktaları yaratılarak, bağlantının bütünlüğünün sürdürülmesi için kullanılmaktadır. Türkiye de mekanik konektör alanında ciddi bir açık bulunmaktadır. Kullanılan mekanik konektörlerin hepsi ithal edilmektedir. Kullanım yerlerine göre bakır veya alüminyum olmak üzere iki türdür.

Kompresyon Konektör: Mekanik konektörlerdeki gibi temas noktaları yaratılarak bağlantının bütünlüğünü sağlamaktadır. Buradaki fark bu bağlantının yüksek bir güç vasıtasıyla konektörün iletkenlere tutturulmasıyla sağlanması işlemidir. Kompresyon konektörlerin montaj1 sirasında hidrolik pres ve bu preste konektör çapına uygun kablo üzerinde istenilen sıkıştırmayı sağlayacak farklı boyutlarda materyaller kullanılmaktadır.

Füzyon Konektör: Füzyon konektörler, kompresyon ve mekanik konektörler ile aynı amacı elde etmek için kaynak, lehim veya pirinç ile kaplama yapılarak bağlantı sağlanmaktadır.

\subsection{Konektör Bozunma Mekanizmaları}

Konektör bozunma mekanizmalarının anlaşllabilmesi için öncelikle konektörün kritik komponentlerin iyi analiz edilmesi gerekmektedir. Birbirine temas eden iki yüzey arasından elektrik akımı geçtiğinde, akımın geçtiği gerçek alan toplam temas yüzeyinin sadece küçük bir kısmını oluşturmaktadır. 
Elektriksel kontağın sağlandığı yüzeyin alanı kontakları birbirine tutturan kuvvetin büyüklüğüyle doğru orantılıdır, bu yüzden eklemlerdeki rezistans iletkenin toptan rezistansından çok daha yüksek bir değere sahiptir. Akım az sayıda ve az boyutta spottan aktığı için bu spotlardaki akım yoğunluğu devrenin kalanına göre daha şiddetlidir, bu durum temas yüzeyinde sıcaklığın balk kısma göre yüksek olmasının yanında erozyon ve kaynak gibi birçok deformasyonun oluşmasına da sebep vermektedir.

Diğer bir teknik problem ise konektörlerde karşılaşılan stres gevşemesi ve şekil değiştirme hassasiyeti konusudur. Malzeme belli bir zaman, sabit bir dış kuvvete maruz bırakılırsa sünme (creep) oluşur. Sünmenin oluşma hızı stresin büyüklüğüne, sicaklığa ve malzeme cinsine bağlıdır. Malzemenin elektrik akımı taşıması sünmenin ve gerilme gevşemesi stress relaxation hızının katlanmasına sebep olur. Vidaları montaj aşamasında çok sıkmak, eklemin sağlam olmasına katkıda bulunmaz. Aksine sünme ve stress relaxation hızının yüksek olmasına neden olmaktadır. $\mathrm{Bu}$ nedenle vidalar olabildiğince az sıkılmalıdır.

Bir diğer teknik problem de korozyon ve oksitlenme problemidir. Bunun yanında karşılaşılan diğer bir problem de dalgalanma aşınımıdır (Fretting). Dalgalanma aşınımı kontak yüzeylerin sert kısımlarında oluşan korozyona karşılık gelmektedir. Bu tip aşınım yük altında ve tekrarlı yüzey hareketleri sonucunda oluşmaktadır.

Mekanik konektörün de yük altında olması ve sürekli değișen akımlardan dolayı termal salınıma maruz kalarak temas eden yüzeylerin termal genleşme ve mekanik titreşimlere maruz bırakılması neticesinde, dalgalanma aşınımı konektör başarısızlığında önemli rol oynamıștır. Bununla birlikte dalgalanma aşınması neticesinde mekanik konektörlerin stabilitelerinin kaybolduğu gözlenmiştir.

\subsection{Mekanik Konektör Tasarım Gereksinimleri}

Tasarım çalışmaları sırasında mekanik yükleme, yüzey durumu, malzeme uyumluluğu ve yüzey sertliği gibi önemli tasarım kriterleri dikkate alınarak mekanik konektör geliştirilmiştir.
Mekanik Yükleme: Mekanik yükün kontak direncine bağlı olması kabul gören bir gerçektir. Bunu takiben tasarımın gerilim gevşemesine ve elektriksel yük altında diferansiyel termal genleşmeye izin vermesi gerekmektedir. Herhangi bir konektör tasarımında doğru sıkıştırma basıncının başarıldığının ve sürdürüldüğünün sağlandığı kanıtlanmalıdır. Bunlara ilaveten herhangi bir özel ekipmana ve yeteneğe gereksinim duyulmadan konektörün birleştirilmesi bu aşamada hesaplanmalıdır.

Yüzey Durumu: Performans ve güvenirlik için mekanik yükleme kadar önemli bir diğer unsurda yüzey durumudur. Birbirine yaklaştırılmış iki metal yüzey düşünüldügünnde, yüzeylerin gözle görülür pürüzlülüğüne neden olan noktalar ve pürüzler bulunur. Yüzeyler birbirine yaklaştırıldığında, başlangıç kontağı bu noktalarda zirveye ulaşır. Yüzey pürüzlülük derecesini artırmakla kontak direnci düşürülmüş olur. Ürünün ömrünün uzatılması için bu çok önemli bir unsurdur.

Malzeme Uyumluluğu: Kullanılan malzemenin alaşımı tasarım yaparken dikkate alınması gereken bir diğer unsurdur. Alüminyumdan konektör tasarımı yaparken belirli kablo ebatlarını ve konfigürasyonlarını karşılamalıdır. Malzeme farklılığından dolayı (Bakır iletken - Alüminyum konektör) iletkenler ve konektör arasındaki direnç dikkate alınmazsa oluşacak dirençten dolayı sistemin zarar görmesi muhtemeldir.

Yüzey Sertliği: Konektör ve iletkenin yüzey sertliği kontak direncinin beklenenden daha az bir etkiye sahip olduğunu gösterir ama bakır/alüminyum sürtünme katsayısının alüminyum/alüminyum dan daha düşük olduğu yerlerde bağlantının gerilme kuvvetine etki eder. İnce pirinç geçiş malzemesi sayesinde sürtünme katsayıs1 arttırılarak bakır/alüminyum bağlantının gerilme kuvvetine katkı sağlanır.

\subsection{Tasarım ve Analiz Materyalleri}

Mekanik konektör çizimleri ve cıvataların çizimleri AutoCAD (teknik resim) ve SolidWorks CAD (kat1 modelleme ve montaj) programı vasitasıyla gerçekleştirilmiştir. Konektörün teknik resimleri ve 
modellemeler tamamlandiktan sonra ANSYS ile analiz programlarıyla beraber mukavemet analizleri yapılmıştır. Böylece konektör için farklı tipte modellemelerle en iyi performansı elde etmek için gerekli bilgisayar simülasyonları oluşturulmuştur. Bilgisayar analizlerinde materyal olarak Al 6063 kullanılırken üretim için malzeme alımında piyasada daha çok yaygın olarak kullanılan Al 6082-T6 ile yapılmasına karar verilmiş ve bu malzemeye uygun analizler tekrar yapılmıştır. Üretimde testler için açısal olarak farklı cıvata yerlerine sahip farklı konektör tasarımı oluşturulmuştur. Seri üretim ve imalat sürecinde malzeme tedariki sağlandıktan sonra gerekli üretim planı çıkarılmıştır. Bu doğrultuda konektör ve cıvata üretimi yapılmıştır.

\section{BULGULAR VE TARTIŞMA}

\subsection{Mekanik Tasarım}

Tasarımı yapılan mekanik konektörün bölümleri Şekil 1'de gösterilmiş olup konektör; vida delikleri (1), tutucu delikler (2), konektör duvar kısmı (3), adaptör parçaları (4), tutucu deliklerin olduğu kısım (5), iç kanal (6), dış katı tabaka (7), vidanın baş (somun) kısmı (8) ve vidanın gövde kısmı (9) bölümlerinden oluşmaktadır.
Elektrik kablo bağlantılarını sağlayan konektörün genel olarak gövdesinde belirli açılarla yerleştirilmiş konektör vida delikleri (1) bulunmaktadır. Konektör vida delikleri (1) sayı ve açılı düzen bakımından $120^{\circ}$ ve $90^{\circ}$ açıyla yerleştirilerek konektör iç kanalından (6) geçen elektrik kablosunu konektör vidasının gövde kısmı (9) sayesinde tutmaya yarar. Konektör vidası, vida baş (somon) kısmı (8) ve vida gövde kısmı (9) olarak iki kısımdan oluşmaktadır. Konektör vidasının en büyük özelliklerinden biri belirli bir tork değeri ile sıkılırken sınır tork değerine ulaşıldığında vida baş (somon) kısmının (8) koparak sadece gövde kısmının (9) konektör dış katı tabakası (7) boyunca dolgu yapması ve konektör iç kanalından (6) geçen elektrik kablosunu belirli bir oranda sıkıştırarak bağlantı sağlamasıdır. Konektör parçası pirinç malzemeden talaşlı imalat yöntemi ile üretilmektedir. Pirinç blok malzemeden önce konektör iç kanalı (6) açılır. Konektör iç kanalı (6) içerisinde tam orta noktada konektör içerisinde su ilerlemesini önlemek amaciyla bir duvar kısmı (3) bulunmaktadır. Konektör iç duvar kısmı (3), konektör iç kanalında (6) belirli bir genişlik ve yükseklikte bırakılan katı malzeme tabakasıyla oluşur. $\mathrm{Bu}$ kısım uzun hatlar boyunca çekilen kablolar arasına herhangi bir nedenle su sızması olduğunda bu sıan suyun tüm hat boyunca ilerlemesini önleyerek sadece o kısımda lokal olarak bir bakım yapılmasına neden olarak tüm hattın bakımdan ve onarımdan geçmesini önlemektedir.

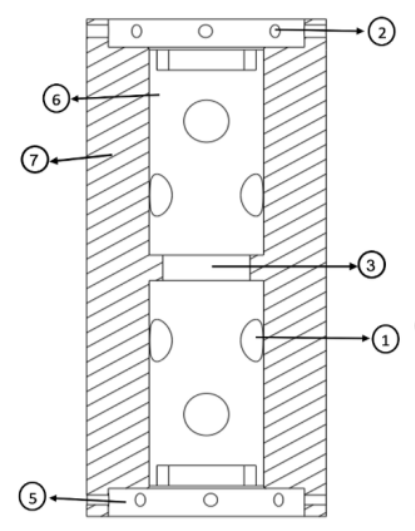

a)

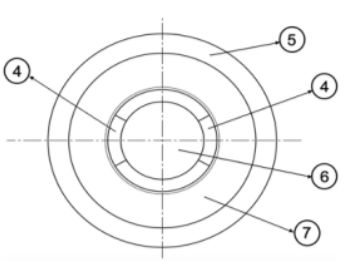

b)

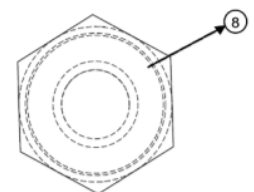

c)

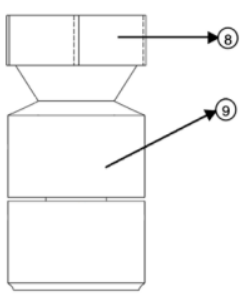

d)

Şekil 1. M120-8'e (120 aralıkla 8 hizalı olmayan cıvata) ait a) konektörün kesit görünümü, b) konektörün üstten bakış görünümü, c) konektör vida üstten bakış görünümü d) konektör vida önden bakış görünümü 
Konektörün her iki uç kısmında da konektör dış katı tabakasının (7) talaşlı imalatla inceltilmesiyle oluşturulmuş, daha ince bir tabaka (tutucu deliklerin olduğu kısım (5)) bulunmaktadır. Bu kısımda konektör üzerine kaplanacak koruyucu kısmı bağlayan tutucu delikleri (2) bulunmaktadır. $\mathrm{Bu}$ küçük tutucu delikler (2) konektörün bağlanması sırasında dış ortam koşullarına karşı konektörü koruyan tabakanın, konektörden ayrılmamasını sağlamaya yarar. Tutucu delikler (2), koruyucu tabaka konektör üzerine kaplandığında bu tabakayı tutturmak için kullanılan bağlama kablolarının geçtiği yerlerdir. Konektör diş katı kısmı (7) uç kısımlara doğru inceltilerek koruyucu kaplama malzemesini tutan tutucu deliklerin (2) açılması nedeniyle tutucu deliklerin olduğu kısım (5) oluşturulur. Konektörler farklı çaptaki kabloların bağlanması için her iki uç kısmında da bağlanacak kablonun çapına uygun bir adaptör parçası (4) içermektedir. $\mathrm{Bu}$ adaptör parçaları (4) ile konektörün kullanılabileceği çok sayıda değişik çaptaki kablolar da konektöre bağlanabilmektedir. Adaptör parçaları (4) tutucu deliklerin olduğu kısma (5) yerleştirilerek konektörün iç kanalından (6) geçen elektrik kablosunu tutarak, kablonun her iki uç kısımda da sabitlenmesini sağlamaktadır.

$90^{\circ}$ aralıklarla hizalı 8 ve 12 cıvata deliği bulunduran ve $120^{\circ}$ aralıklarla hizalı olmayan 8 ve 12 c1vata deliğinden bulunduran toplamda 4 farklı çeşit olmak üzere mekanik konektör tasarımı yapılmıştır. Konektör isimlendirmesi Çizelge 1'de verilmiştir. Şekil 2'de M90-12 ve M120-8 teknik resimleri verilmiştir.

Çizelge 1. Konektör tasarım özellikleri ve isimlendirmesi

\begin{tabular}{|c|l|l|}
\hline No & $\begin{array}{l}\text { Konektör } \\
\text { İsimlendirme }\end{array}$ & Açıklama \\
\hline 1 & M90-8 & $90^{\circ}$ aralıkla 8 hizalı c1vata \\
\hline 2 & M90-12 & $\begin{array}{l}90^{\circ} \text { aralıkla 12 hizalı } \\
\text { c1vata }\end{array}$ \\
\hline 3 & M120-8 & $\begin{array}{l}120^{\circ} \text { aralıkla 8 hizalı } \\
\text { olmayan c1vata }\end{array}$ \\
\hline 4 & M120-12 & $\begin{array}{l}120^{\circ} \text { aralıla 12 hizalı } \\
\text { olmayan cıvata }\end{array}$ \\
\hline
\end{tabular}
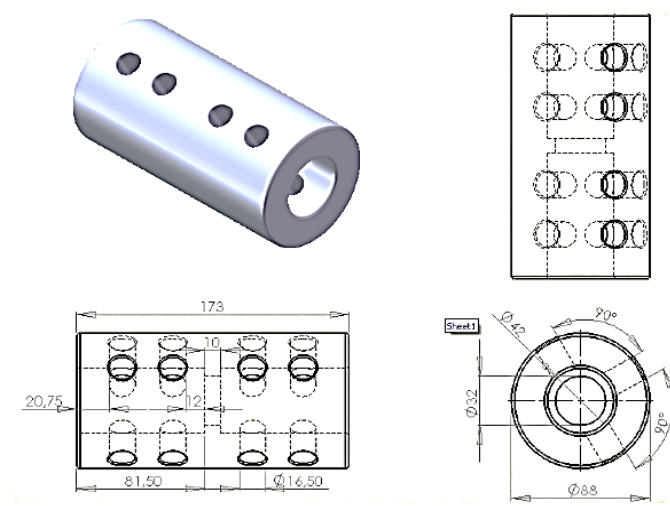

a) $\mathrm{M} 90-12$
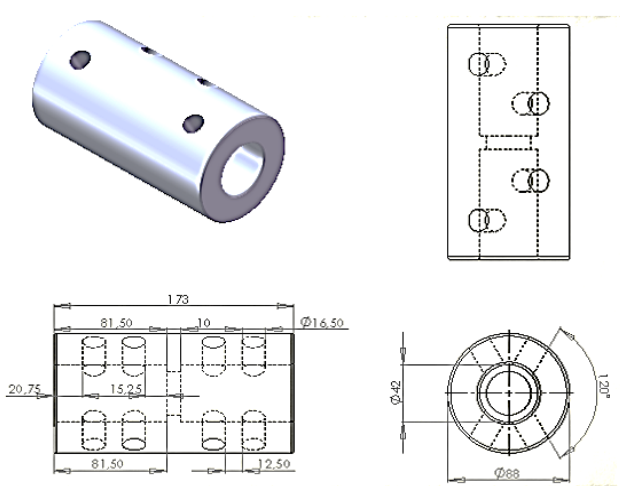

b) $\mathrm{M} 120-8$

Şekil 2. M90-12 (90 aralıkla 12 hizalı cıvata) ve M120-8 (120 aralıkla 8 hizalı olmayan c1vata) konektörlerinin teknik resimleri

\subsection{Mukavemet Analiz Çalışmaları}

SolidWorks ortamında yapılan mekanik tasarımların mukavemet analizleri gerçekleştirilmiştir. Konektör ve delikleri üzerinde yükler tanımlandıktan sonra sonlu eleman ağ1 (mesh) oluşturulmuş ardından çözüm yaptırılmıştır. Çözüm sonlanmasını takiben sonuçların işlenmesi/görüntülenmesi sağlanmıştır. Çözüm sonuçları alınırken yer değiştirme ve güvenlik katsayıs1 (factor of safety (fos)) verileri değerlendirilmek üzere görüntülenmiştir. Şekil 3'de tüm konektörlere ait analiz görüntüleri mevcuttur. Çizelge 2'de herbir konektördeki maksimum yer değiştirme (m) ve güvenlik katsayısı değerleri verilmiştir. 


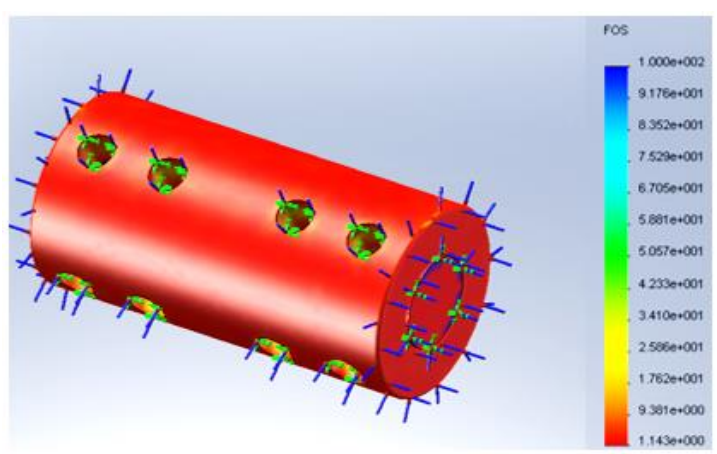

M90-8

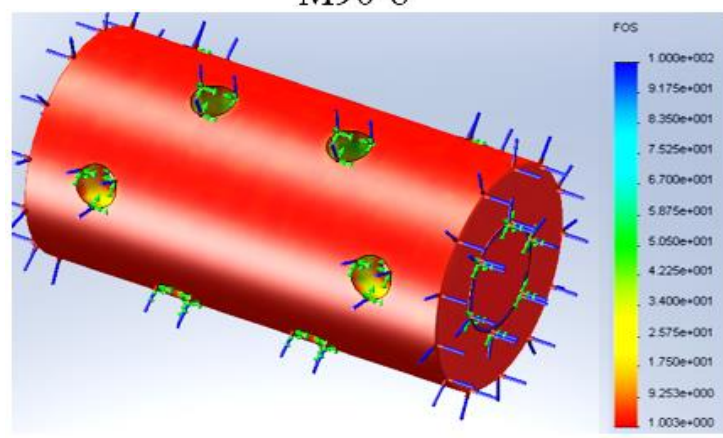

M120-12

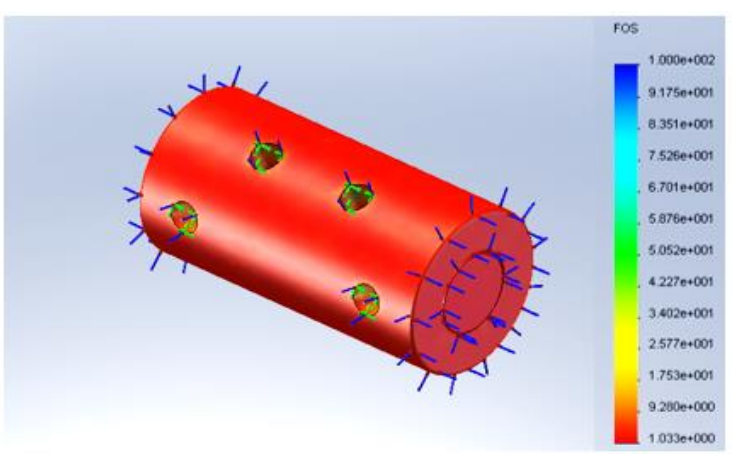

M120-8

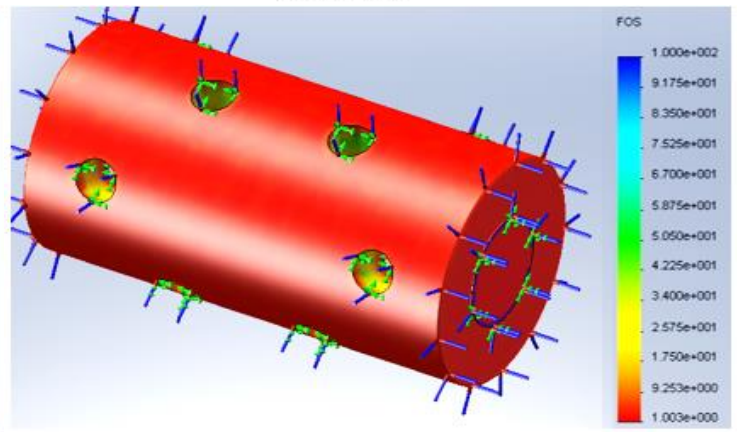

M120-12

Şekil 3. Konektörlerin simülasyon görüntüsü

Çizelge 2'de her bir konektördeki maksimum yer değiştirme (m) ve güvenlik katsayısı değerleri verilmiştir.

Çizelge 2. Simülasyon sonuçları

\begin{tabular}{|c|c|c|}
\hline Konektör & $\begin{array}{c}\text { Yer Değiştirme } \\
\text { (Displacement) } \\
(\mathrm{m})\end{array}$ & $\begin{array}{c}\text { Güvenlik Katsayis1 } \\
\text { (FOS-Factor of } \\
\text { Safety) }\end{array}$ \\
\hline $\mathrm{M} 90-8$ & $3,6^{*} \mathrm{e}-5 \mathrm{~m}$ & 1,143 \\
\hline $\mathrm{M} 90-12$ & $6,1 * \mathrm{e}-5 \mathrm{~m}$ & 1,05 \\
\hline $\mathrm{M} 120-8$ & $4,44 * \mathrm{e}-6 \mathrm{~m}$ & 1,33 \\
\hline $\mathrm{M} 120-12$ & $4,1 * \mathrm{e}-6 \mathrm{~m}$ & 1,21 \\
\hline
\end{tabular}

Birçok mekanik sistemde güvenlik katsayısı 1'den büyük olması beklenir. Çizelge 2'de görüldüğü üzere çalışmada tasarlanan 4 farklı konektörün de analiz sonucunda güvenlik katsayıları 1'den büyüktür. M120-8, diğer konektörlere k1yasla en yüksek güvenlik katsayısı sonucunu vermiştir. M120-8 konektörünün, en düşük güvenlik katsayısına sahip M90-12'nin 1,27 katı kadar yani $\% 27$ daha fazla güvenlik katsayına sahip olduğu gözlemlenmiştir. Yer değiştirme verileri incelendiğinde M120-12 en az M90-12 konektöründe ise en çok yer değiştirme görülmüştür. En yüksek yer değiştirme sonucunu veren M90-12'nin, en düşük yer değiştirmeye sahip M120-12'nin 14,9 katı kadar değeri olduğu gözlemlenmiştir. Güvenlik katsayıs1 karşılaştırıldığında M120-8, yer değiştirme verileri karşılaştırıldığında ise M120-12'nin değerleri daha iyi çıkmıştır. Hem yer değiştirme hem de güvenlik katsayısı verileri kıyaslandığında $120^{\circ}$ açı aralıklı vida deliklerine sahip konektörler $90^{\circ}$ 'liklerden daha iyi sonuçlar verdiği görülmüştür. $90^{\circ}$ aç1 aralıklı tasarımlar hizalı vida deliklerine sahipken $120^{\circ}$ açı aralıklılar sıralı olmayıp vida delikleri dağıtılmıştır. $120^{\circ}$ açı aralıklılarda vida deliklerindeki yüklerin dağıtılmış olmasının bu veriler üzerinde pozitif etkisinin olduğu sonucu çıkarılabilir.

\subsection{Performans Testi}

Üretimi yapılan prototipler, elektriksel fabrika 
testlerine tabi tutulmuştur. Şekil 4 'te test ortamı ve test düzeneği gösterilmiştir. Test düzeneği güç (besleme) sistemi ve konektörlerin bulunduğu yüksek gerilim hattından oluşmaktadır.

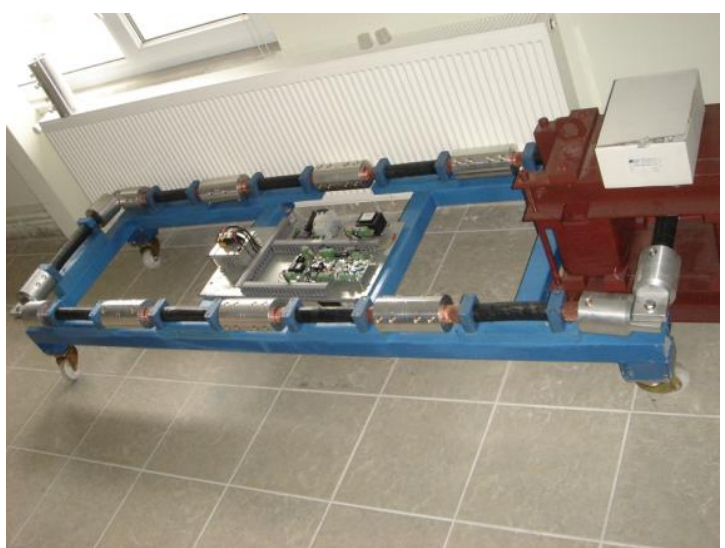

Şekil 4. Test düzeneği

Birbirine bağlanan iletkenler arasında uygulanan her biri 70 dakika süreyle 50'şer yük çevrim testi yapılmıştır. $\mathrm{Bu}$ operasyondan sonra sistem 40 A 1 sn. süreli kısa devre testine tabi tutulmuştur. Konektörler arasındaki dirençten kaynaklanan gerilim düşüşünü ölçmek için dijital voltmetre ve akım kaynağı kullanılmıştır.
Yüksek gerilim hattının çalışma senaryosu incelendiğinde devrede 40+-15 A yüksek akım dolaşacağından bakır tel ve konektörlerde aşırı 1sınma sebebiyle genleşme meydana gelecektir. Yüksek gerilim hattında iletimi sağlayan bakır telin genleşme miktarıyla alüminyum malzeme konektörün genleşme miktarı farklıdır. Genleşmeyle meydana gelen Alüminyum konektörlerdeki şekil değişimi Bakır telden daha fazla olacağından birbirlerine temas ettikleri bölgede boşluk meydana gelecektir. Buna ek olarak iletken 1sınacağından direnç değerlerinde değişim meydana gelecektir. Eşitlik 1'de iletkenin direncinin sıcaklığa göre değişimini gösteren eşitlik verilmiştir [25]. $T_{0}$ başlangıç sicaklık $\left({ }^{\circ} \mathrm{C}\right), R_{0}$ $T_{0}$ ' daki direnç (ohm), $T$ mevcut sicaklık $\left({ }^{\circ} \mathrm{C}\right), R$ mevcut direnç (ohm), $\alpha$ direnç değişim katsayısı değeridir.

$R=R_{0}\left(1+\alpha\left(T-T_{0}\right)\right)$

Konektörlerin bulunduğu bağlantı bölgesinde ilk $\left(20{ }^{\circ} C^{\prime}\right.$ de $)$ ve son $\left(27{ }^{\circ} C^{\prime}\right.$ de $)$ ölçülen direnç değerleri $(\mu \Omega)$ Şekil 5 ve hesaplanan voltaj değerleri $(\mathrm{mV})$ Şekil 6'da grafik üzerinde verilmiştir. Grafiklerin sol ölçek çubuğunda ölçülen değerler gösterilirken sağ ölçek çubuğunda son ve ilk ölçülen değerler arasındaki fark gösterilmiştir.

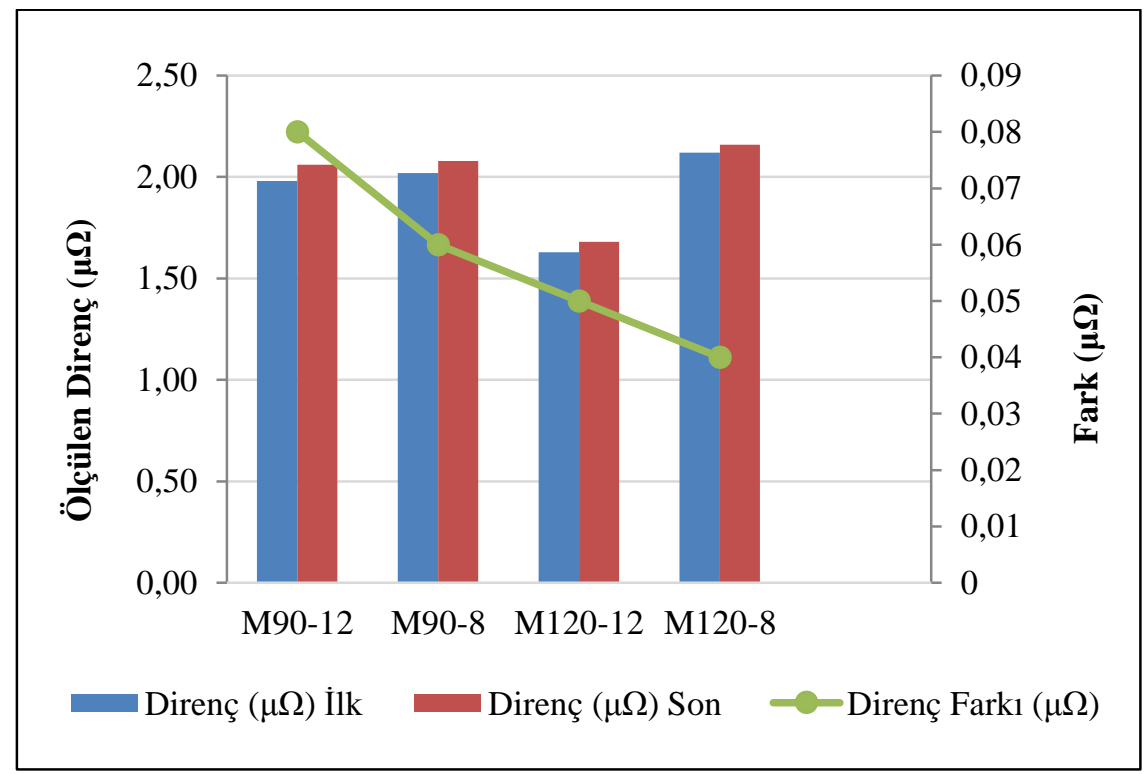

Şekil 5. Konektörlerin ilk ve son direnç değerlerini gösteren grafik 


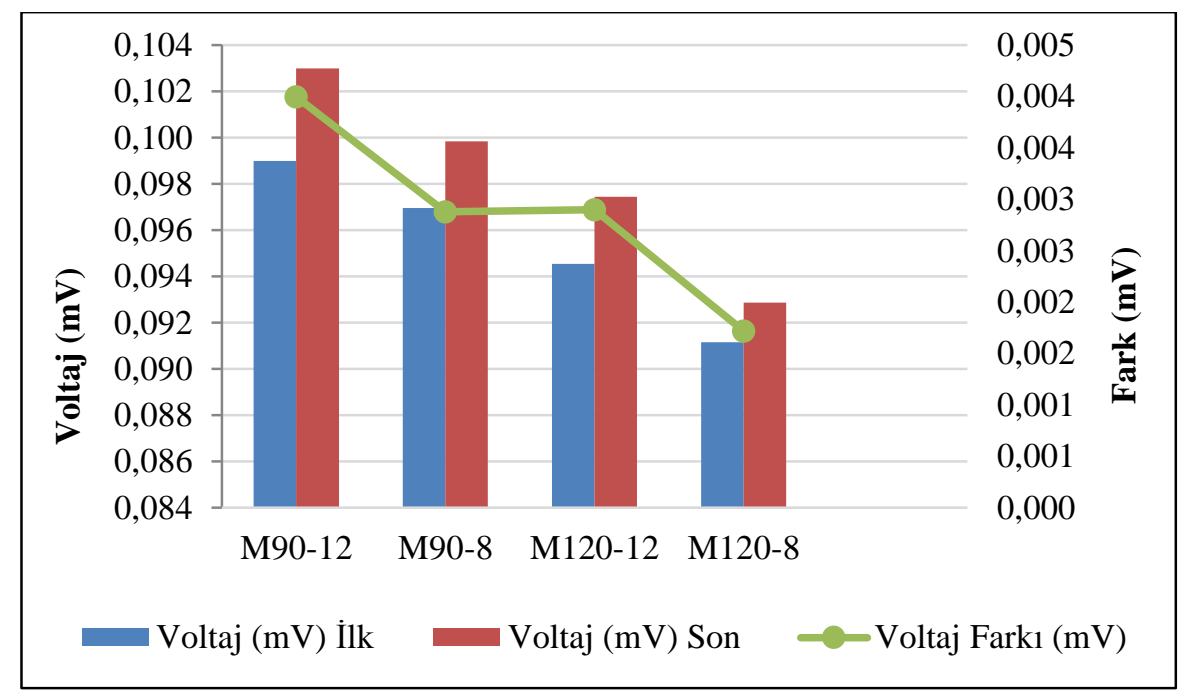

Şekil 6. Konektörlerin ilk ve son voltaj değerlerini gösteren grafik

Direnç grafiğinde en az direnç artışı M120-8 konektöründe olduğu gözlemlenmiştir. M120-8 konektöründe ilk direnç $2,12 \mu \Omega$ son direnç $2,16 \mu \Omega$ olup direnç \%1,87 artmıştır. Direnç değişimine bağlı olarak voltaj değerindeki en az artış da M1208 konektöründe olup bu değer 0,002 mV'dur. En az direnç artışı M120-8 de meydana geldiğinden nihai tasarım olarak seçilmiştir.

\section{SONUÇ VE ÖNERÍLER}

Bu çalışmada mekanik ve malzeme avantajlarından dolayı yüksek gerilim hatlarında kullanılmak üzere mekanik konektör tasarımının geliştirilmesi amaçlanmıştır. Çalışmada $90^{\circ}$ ve $120^{\circ}$ açı aralıklı vida deliklerine sahip toplamda 4 farklı tasarım yapılmıştır. Tasarımı takiben prototip üretimi yapıldıktan sonra gerekli simülasyon ve testlerin uygulanarak optimum özelliklere sahip mekanik konektörün geliştirilmesi sağlanmıştır. Mukavemet simülasyon testlerinde yer değiştirme ve güvenlik katsayısı değeri bakımından M120-12 ve M120-8 isimli konektörler en iyi sonuçları vermiştir. Yük çevrim testi uygulanarak yapılan performans testlerinde direnç, akım ve voltaj değerleri ölçülmüştür. Özellikle direnç değerlerindeki ilk ve son ölçüm farkına göre M120-8 konektörü en optimal sonuçları verdiği gözlemlenmiş olup kullanım için uygunluğu ortaya koyulmuştur.
Konektörün detaylı tasarımı sonucu sahip olduğu mekanik özellikler değerlendirildiğinde kullanımının daha pratik ve farklı çaptaki kablolara uygulanabilir olması öne çıkmaktadır. Konektör parçasının geometrisinin ve konstrüksiyonunun geliştirilmesiyle daha uygun fiyatta teknik özellikleri daha yüksek konektör geliştirilmiştir. Yapılan tasarım sayesinde konektörün iletkenle temas halinde bulunduğu bölümlerde iletkenin oksit tabakası üzerinde hiçbir şekilde tahribata neden olmamaktadır. Bu duruma ilaveten geliştirilecek mekanik tasarım sayesinde konektörün beklenmedik büyüklükteki gerilme kuvvetlerine karş1 direnç göstermesi sağlanmıştır. Montaj sırasında hidrolik prese ve özel sıkma çenelerine gerek duyulmamaktadır. Mekanik parçaların montajı diğer konektörlere göre daha kolay ve emniyetli bir şekilde yapılmaktadır. Mekanik tasarım sayesinde iletken çapı ile konektör çapı aynı seviyeye getirilebilmekte ve elektrot izolasyon çap1 aynı olduğu için ekstra bir elektrot elemanına gerek duyulmamaktadır. Ayrıca konektörün iletkenle temas halinde bulunduğu bölümlerde iletkenin oksit tabakası üzerinde hiçbir şekilde tahribata sebebiyet vermemektedir. Konektörde kullanılan vidaların s1kma kuvvetleri hassas olarak ayarlanarak konektörün 1sınması sırasında genleşmesine imkân sağlayarak aynı zamanda uygun sıkma kuvveti değerlerinde kalıp diğer yandan da vidaların uygun 
değerde kuvvetle sıkılarak konektörün içindeki kablolara zarar vermemesi de sağlanmaktadır.

Parçanın elektriksel tasarımı sayesinde konektörün düşük kontak direncine sahip olması sağlanmıştır. Bu nedenle konektör üzerinde kıvrımlar yaratılarak temas yüzeyleri artırılmış ve bu sayede de daha az kontak direncine sahip olması sağlanmıştır. Daha az kontak direncinin olması ile de kayıplar ve konektörün ısınması engellenmiştir. Sizdırmazlık yüzeyinden beklenmedik bir nedenle kabloların açık olan uçlarındaki kılcal tellere sızan su, eğer konektör arasında herhangi bir sızdırmazlık unsuru yoksa diğer kabloya ulaşması muhtemeldir. Buda her iki taraftaki hatta da zarara neden olmaktadır. Konektör üzerinde geliştirilen özel bölme sayesinde suyun kablo içinde ilerlemesi engellenerek, oluşabilecek zararların en aza indirilmesi sağlanmıştır. Konektörün ortasında açılan kanal dışarıdan gelen suyun bağlantının diğer tarafına geçmesine engel olarak hattın güvenliğini sağlamaktadır.

\section{KAYNAKLAR}

1. Braunovic, M., 2004. Effect of Connector Design on the Performance of Service Entrance Power Connectors Components and Packaging Technologies, IEEE Transactions on Components and Packaging Technologies, 27, 72-78.

2. Naybour, R. D., Farrell, T., 1973. Connectors for Aluminum Cables: A Study of the Degradation Mechanisms and Design Criteria for Reliable Connectors. IEEE Transactions on Parts, Hybrids and Packaging, 9(1), 30-36.

3. Frank, R. F., Morton, C. P., 2007. Comparative Corrosion and Current Burst Testing of Copper and Aluminum Electrical Power Connectors, IEEE Transactions on Industry Applications, 43(2), 462-468.

4. Mainier, L., 1990. Connection Technique for Aluminum Conductors in LV and MV Power Distribution Systems-Characteristics and Field Experience, Thirty-Sixth IEEE Conference on Electrical Contacts, and the Fifteenth International Conference on Electrical Contacts, Montreal, QC, Canada, 1990, 487-492.
5. Braunovic, M., 1990. Evaluation of Different Contact-aid Compounds for Aluminum-tocopper Connections, Thirty-Sixth IEEE Conference on Electrical Contacts and the Fifteenth International Conference on Electrical Contacts, Montreal, QC, Canada, 1990, 509-517.

6. Joyce, C.F., 1991. A Weibull Model to Characterize Lifetimes of Aluminum Alloy Electrical Wire Connections, IEEE Transactions on Components, Hybrids and Manufacturing Technology, 14(1), 124-133.

7. Braunovic, M., 1994. Aluminium Connections: Legacies of the Past, Proceedings of IEEE Holm Conference on Electrical Contracts, Chicago, IL, USA, 1994, 1-31.

8. Braunovic, M., 1986. Effect of Contact Aid Compounds on the Performance of Bolted Aluminum-to- Aluminum Joints Under Current Cycling Conditions, IEEE Transactions on Components Hybrids and Manufacturing Technology, 9(1), 59-70.

9. Braunovic, M., 1988. Fretting Damage in Tinplated Aluminum and Copper Connectors, Electrical Contacts, Proceedings of the Thirty Fourth Meeting of the IEEE Holm Conference on Electrical Contacts, San Francisco, USA, 1988, 179-186.

10. Runde, M., Magnusson, N., Lenes, A., 2008. Bolted Connectors for Stranded Aluminum Power Conductors, IEEE Transactions on Power Delivery, 23(2), 523-530.

11. Dang, C., Braunovic, M., 1989. Metallurgic and Contact Resistance Studies of Sleeve Connectors in Aluminium Cable Splices, Proceedings of the Thirty Fifth Meeting of the IEEE Holm Conference on Electrical Contacts, Chicago, USA, 1989, 229-236.

12. Haverkamp, W. B., McKoon, T., Wilck, M., 1999. Bolted Connectors for High Voltage Accessories Installed on Underground Transmission Lines, IEEE Transmission and Distribution Conference (Cat. No. 99CH36333), LA, USA, 1999, 74-82.

13. Tuna, E., Kraus, J., 2016. Design and Production of High Voltage Cable Accessories in Turkey, Güç Sistemleri Konferans1, İstanbul, Türkiye, 34-42. 
14. Facilities Engineering Branch Denver Office, August 2000. Facilities Instructions, Standards, and Techniques: Electrical Connections for Power Circuits, Volume 3-3, Denver, Colorado.

15. Sönmez, F., Başak, H., 2016. Sürtünme Karıştırma Kaynağının Yaşlandırılabilir Parçalar Üzerinde Etkisi. Çukurova Üniversitesi Mühendislik-Mimarlık Fakültesi Dergisi, 31(1), 29-34.

16. Haim, K., Cisilino, D., Bentkowski, K., 2009. The Behavior of Shear Bolt Connectors in MV Cable Accessories in Case of Critical Load and Overload, CIRED 2009-20 $0^{\text {th }}$ International Conference and Exhibition on Electricity Distribution-Part 1, Prague, Czech Republic, 2009, 1-4.

17. Yang, F., Zhu, N., Liu, G., Ma, H., Wei, X., Hu, C., Wang, Z., Huang, J., 2018. A New Method for Determining the Connection Resistance of the Compression Connector in Cable Joint, Energies-section Electrical Power and Energy System, 11(7).

18. Hernandez-Guiteras, J., Riba, J., CasalsTorrens, P., 2013. Determination of the Corona Inception Voltage in an Extra High Voltage Substation Connectori, IEEE Transactions on Dielectrics and Electrical Insulation, 20(1), 82-88.

19. Nexans Power Accessories 2017. Bolted Connectors, Ürün Kataloğu.

20. Ruan, J., Liu, C., Huang, D., Zhan, Q., Tang, L., 2016. Hot Spot Temperature Inversion for the Single-core Power Cable Joint, Appl. Therm. Eng., 104, 146-152.

21. Fu, J., Cheng, P., Chen, W., Hu, X., Wang, Q., Yang, Q., Yang, F., 2016. Investigation of the Effects of Insulation Defects on the 3-D Electromagnetic-thermal Coupling Fields of Power Cable Joint, in Proceedings of the IEEE Conference on Industrial Electronics and Applications, Hefei, China, 5-7 Haziran 2016, 1436-1439.

22. Liu, Y., Liu, G., Wang, Z., Xu, T., Xu, U., 2016. Experimental Analysis on Crimping Resistance of Connecting Pipe of Cable Intermediate Joint, Guangdong Electr. Power, 29, 108-112.

23. Ruan, J., Zhan, Q., Tang, L., Tang, K., 2018. Real-time Temperature Estimation of Three- core Medium-voltage Cable Joint Based on Support Vector Regression. Energies, 11, 1405. 24. Yang, F., Cheng, P., Luo, H., Yang, Y., Liu, H., Kang, K., 2016. 3-D Thermal Analysis and Contact Resistance Evaluation of Power Cable Joint, Appl. Therm. Eng., 93, 1183-1192.

25. Kasap, S.O., 2006. Principles of Electronic Materials and Devices (Third ed.), Mc-Graw Hill, Boston, 874.

26. Dag, M., Akcay, N., Koten, H., Guner, K., 2019. Determination of Photovoltaic Properties for Nanostructures. Journal of Electronic Materials, 48(11), 6919-6931. 
